\title{
Erratum: Supratentorial primitive neuroectodermal tumor metastasis to the abdomen via a ventriculoperitoneal shunt
}

\author{
David T. Boyd • Mohammad R. Hayeri • Pranav K. Vyas
}

Published online: 15 January 2011

(C) Springer-Verlag 2011

Erratum to: Pediatr Radiol

DOI 10.1007/s00247-010-1732-5

The original version of this article unfortunately contained a mistake. The affiliations were incorrect. The correct information is given below.

The online version of the original article can be found at http://dx.doi. org/10.1007/s00247-010-1732-5.

D. T. Boyd $(\bowtie)$

Department of Radiology, Georgetown University Hospital,

3800 Reservoir Rd., N.W.,

Washington, DC 20007, USA

e-mail: boydd323@aol.com

M. R. Hayeri • P. K. Vyas

Department of Radiology, Children's National Medical Center,

111 Michigan Avenue, N.W.,

Washington, DC 20010, USA 